\section{Brexit delay is hurting dentistry recruitment}

Has the all-encompassing news topic of Brexit and its impact on the UK affected dentistry and the significant minority of overseas trained dentists working here? Adrian O'Dowd investigates.

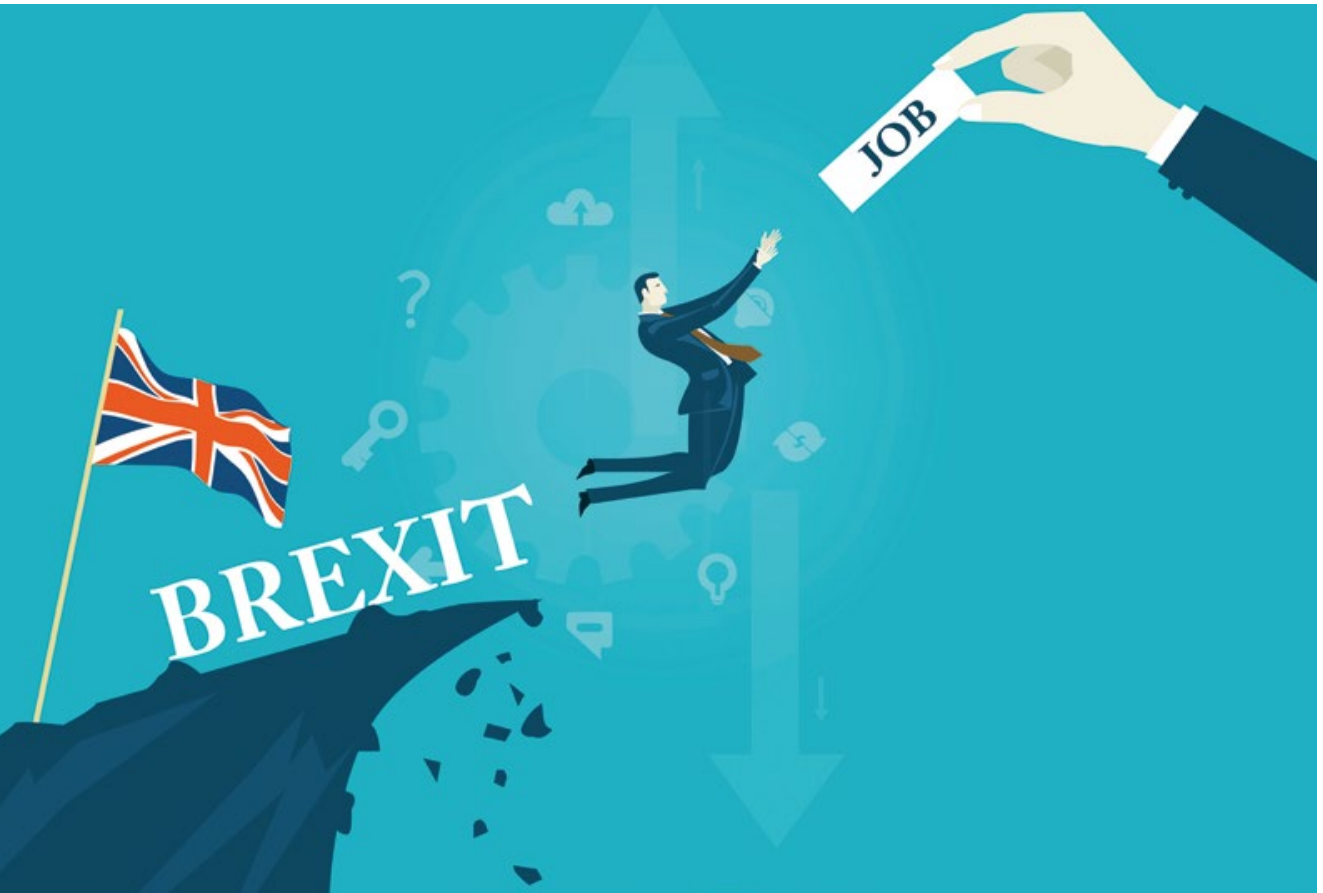

$\mathrm{F}$

ew issues have dominated the headlines over the past year or so more than Brexit, which is likely to affect almost all workforces in the UK, directly or indirectly.

Dentistry is no exception and dental professionals pondering the changes ahead are likely to be noticing how it is starting to make a difference to the workplace and could increasingly do so before the market and workforce settles down.

A significant minority - around a fifth - of the dental profession in the UK is made up of dentists who trained in the European Union (EU).

There appear to be concerns amongst these dentists over their future, demonstrated by a report ${ }^{1}$ published earlier this year by dental regulator the General Dental Council (GDC).

This report on the post-Brexit intentions of European Economic Area (EEA) qualified dental professionals was based in an online survey issued to all these professionals on the GDC register (approximately 6,300 registrants) carried out in the summer of 2018, and gathered responses from 2,464 registrants as well as ten in-depth interviews.

Responses showed that almost a third $(32 \%)$ of those surveyed said they were considering leaving the UK in the next few years, although more than half $(55 \%)$ of this group said this might change if their qualifications continued to be recognised - a promise that the government has now given.

Amongst those intending to leave, $82 \%$ said Brexit and the uncertainty about arrangements for EU citizens living and working in the UK was a significant factor in their reasoning.

The vast majority (84\%) said Brexit was leading to a shortage of healthcare workers in the UK and $75 \%$ agreed it was leading to a shortage of dental professionals.
Many of those interviewed said they had come to the UK originally to work, mostly, for better pay and job availability, and many of those thinking of leaving the UK were considering such a move despite admitting they might earn less money or struggle to find a job.

Others thought that rising wages and shortages of dental professionals in other European countries might make them more attractive than in the UK, particularly given the fall in the value of the pound following the EU referendum on the UK leaving the EU held in 2016.

Head of Regulatory Intelligence at the GDC, David Teeman, says: 'This research was undertaken before important issues have been resolved, such as recognition of qualifications, residency rights and access to the UK for existing and prospective dental professionals.

'Once these issues are settled, we are planning a further round of research which will aim to provide us with increased insight and aid us in our planning.'

No precise date for this second phase of research has been set yet.

\section{Official data clues}

The dental register appears to show there has been an impact of Brexit on new recruits for the workforce.

According to as yet unpublished data seen by the $B D J$, the number of new EEA qualified dentists added to the UK register (who had never been on the UK register before), dropped from 669 in 2015 to just 394 in 2018 (Fig. 1). The downward trend is also evident in 2016 when there were 507 new dentists in that year and 409 in 2017.

However, at the same time, numbers of EEA qualified dentists leaving the register has also fallen in the past few years.

Figures show 515 such dentists left the register in 2016, 456 left in 2017 and 341 left in 2018. It is possible this is an indication that these dentists have decided to stay working here until the situation changes in case leaving and then trying to return later could be difficult.

A report ${ }^{2}$ from Christie \& Co published in October 2018 on workforce challenges in the dental sector analysed official data. It found that dentist numbers in the UK have 


\section{Case study}

Lithuanian dentist Dovile Draugelyte-Spudiene worked in NHS dentistry in the UK for several years after qualifying in her country in 2008, but has now returned home where she has found another job working in her country's equivalent of the public sector.

'I came to the UK in late 2009. My husband, who is an engineer, came to Britain earlier than me and started studying there so I decided to move there to be with him,' she says.

'When I came to the UK, I was living in Reading but I started in Oxford, and worked in a purely NHS practice for seven years. I enjoyed my time but the work was intense. There was a heavy workload and things were done differently in the UK compared to Lithuania.'

Dovile decided to leave the NHS in 2017, a year after the Brexit referendum result, and says it was part of the couple's decision to depart.

'I wouldn't say we left just because of Brexit because we never thought we would stay in England forever, but Brexit was the last straw,' she says.

"A month after the Brexit referendum, my husband said to me "I think it's time to leave". I thought it might become more difficult to carry on working in Britain. I thought sorting out all the documentation for me to become a British citizen would be a hassle.

'We were also worried about the economy and our family lived in Lithuania and might have had travel problems to come and see us.

'As well as Brexit, I didn't much enjoy working for the NHS. It's very stressful and was getting harder. When I came back to Lithuania, I started work and there is much more freedom for dentists and it is more relaxed. It is a better quality of life and we don't have targets to meet like the UDAs in Britain!'

4 been rising steadily in recent years from 38,379 in 2010 to 41,704 in 2017.

However, the supply of dentists was under pressure, particularly in some parts of the UK, such as Wales, the South West, and the East of England.

That report noted that while the number of UK qualified dentists grew year on year since 2014 , over the same period, the number of EEA registered dentists fell for three consecutive years from 2014 to 2016, stabilising in 2017, with the total number of EEA dentists remaining flat.

The report authors said: 'Maintaining and increasing the homegrown supply pipeline of new dentists is important, particularly given uncertainties associated with Brexit and the pressure on existing resource if a greater proportion of the population were to visit a dentist more regularly'.

\section{Future workforce}

The future dental workforce appears to be the area of greatest concern, according to a recently published annual report ${ }^{3}$ about the GDC from the Professional Standards Authority (PSA) - the body that regulates the health regulators.

It showed that the number of applications from EEA registered professionals to get on the UK dental register for 2017-18 fell to 686 from 1,249 in the previous year - a $45 \%$ drop.

Further evidence was shown in the fifth edition of healthcare business market analysts LaingBuisson's Dentistry UK Market Report ${ }^{4}$ published in January 2019, which said that there was a $22 \%$ fall in new dentist registrations in the UK between 2015 and 2017 and a significant drop in new registrations from other origins such as the EU.

This had been worsened by the fact that there was a fall in new dentist registrations coming from the EU, which fell from 970 in 2011 - some $52.7 \%$ of all new registrations in the UK - to a low of 409 in 2017 - some $23.4 \%$ of total new UK registrations.

The authors speculated that the acute falls in 2016 and 2017 could be due to the impact of Brexit.

Martin Woodrow, BDA Acting Chief Executive, believes the various findings offer a complex picture, saying: 'From the research that the GDC did, it talked about sentiment and tells a story of there being a potential Brexit impact and there being almost a third of those who were EEA registered saying they would consider leaving the UK in the next few years.

'We asked the GDC about this and if you compare the number of dentists qualified in the EEA as of 28 February 2018, there were 6,462 registered dentists by qualification from the EEA. That figure, at 1 February 2019, was 6,512 so actually, the figure increased by a very small margin.

'At the moment, the number of registrations by that area as the place of qualification does not appear to have been massively impacted. What that doesn't tell you is what those registrants are doing - whether they are in the UK still practising or not, we don't know.

'However, we also know that the number of applicants from EEA registered professionals has gone down pretty significantly.

'What our practice owner members are telling us is there is a clear recruitment issue in the associate market and it seems likely that part of the issue there is availability of overseas dentists. If you talk to some of the corporates, particularly those that have relied a fair bit on the EEA as a market, they will tell you that that route has dried up considerably.'

\section{Corporate impact}

The fall in interest in coming to the UK has been noted by dental corporate firms such as Colosseum Dental, which operates in eight EU countries and has more than 70 clinics across the south of England.

Its UK chief executive officer Philip Buergin says: 'Brexit is adding a lot of uncertainty for the candidates over what to expect and it has reduced the number of applications and significantly impacted the channel from overseas.

'That doesn't mean it's not going to come back, but it has reduced applications. It's not Brexit itself that has done this, but the uncertainty on what legislation will look like, work permits, and how strong will the pound be against the Euro once things have settled. It has accelerated the shortage in dentistry skills that we see in the UK.'

The company predominantly deals with NHS dentistry and Buergin says it saw dwindling interest start to happen after March 2017 as clinicians were finishing their contracts since the 2016 Brexit referendum and some started to move back home, away from the UK.

'We had people leaving, especially leaving NHS dentistry where you have a lot of dentists from the continent,' he says. 'It had a big impact and there is a fundamental shortage even if Brexit was not happening.

'The other effect has been less applicants coming in. The applicants are still there, but they are on a "hold mode" at the moment. They are saying they are very interested in moving to the UK but they want to wait until Brexit is finalised.

'We also see the pound has depreciated significantly versus the Euro over the past 
three years. The money a dentist can earn in the UK is still significantly higher in the UK than places like Spain and Portugal, but in the past few years, the gap has narrowed.'

\section{Steps to reassure}

It is important to note that the GDC survey of overseas trained dentists was carried out before the government made moves to reassure the healthcare workforce of its continuing role in the UK and sought to give reassurances of how they were valued.

In April 2019, Health \& Social Care Secretary Matt Hancock confirmed that up to 63,000 NHS staff who qualified in the EU or Switzerland would have their training and experience accepted by all regulatory bodies for the health and social care sectors, including the likes of the GDC, General Medical Council and Nursing and Midwifery Council.

In addition, legislation introduced in March 2019 means health and social care workers with professional qualifications from EU and Swiss institutions who are currently registered can continue to practise in the UK as they do now, guaranteeing their ability to work in the NHS.

EU or Swiss qualified people entering the UK after exit may have their qualifications recognised, whether the UK leaves the EU with or without a deal.

The government has said employment contracts would not need to be changed if the UK left the EU without a deal, and staff would not have to reapply for their current positions after exit day.

Woodrow acknowledges the efforts but is realistic about the scale of reassurance needed, saying: 'There have been some supportive messages made across the NHS. NHS dentistry is where we struggle most to recruit when there are recruitment difficulties and our own member surveys suggest NHS dentistry has more of a problem than private practice.

'Positive messages have been put out by the likes of Simon Stevens [NHS England Chief Executive] and NHS Employers saying they value our overseas workforce and EU workforce and we could not operate without them.

'But it was difficult for that voice to be heard amongst the noise being made last year when we were talking about charging people for going through the settled status application. There was an about-turn on that.'

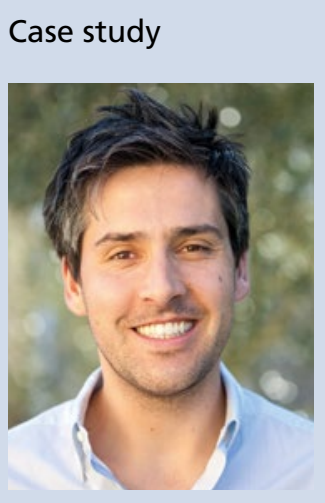

Jose Angelo, an associate working for Colosseum Dental in Cambridge, qualified in 2008 in Portugal and moved to work in the UK immediately.

'I came to the UK as part of gaining experience and as a sort of adventure,' he explains. 'Initially I followed my partner who is a vet and wanted to work here so I went with her. I love it here, the public service, the NHS and how the system operates.

'At first, we thought we would stay just for a year or two. We are settled and happy to stay as long as the promises are kept by the government and the situation doesn't change too much.'

Jose has worked for Colosseum Dental for the past two years and says: 'I started doing NHS work but gradually I have also done private work too. Now I am about 50/50 on NHS and private work.

'Brexit has not affected me directly, but there are some uncertainties about the future. There are lots of people interested in coming here but they don't know what the opportunities and their future would be, how their rights would be applied, and if they would keep authorisation to stay.

'Also, the pound's value has dropped, so the value of working here is not as good as it was before.

'At the moment, the impact of Brexit is negative and there are a lack of dentists and heavy workload. But if promises are kept and everything stays more or less the same and EU nationals keep the same rights as we have now, then I think it will be okay and EU dentists will want to work here again.

'Luckily, at Colosseum Dental we have an amazing team at The Hive (head office) who are incredibly supportive and have a custom-based approach in how to better achieve our targets and maximise our clinical time, somehow easing the increased workload.'

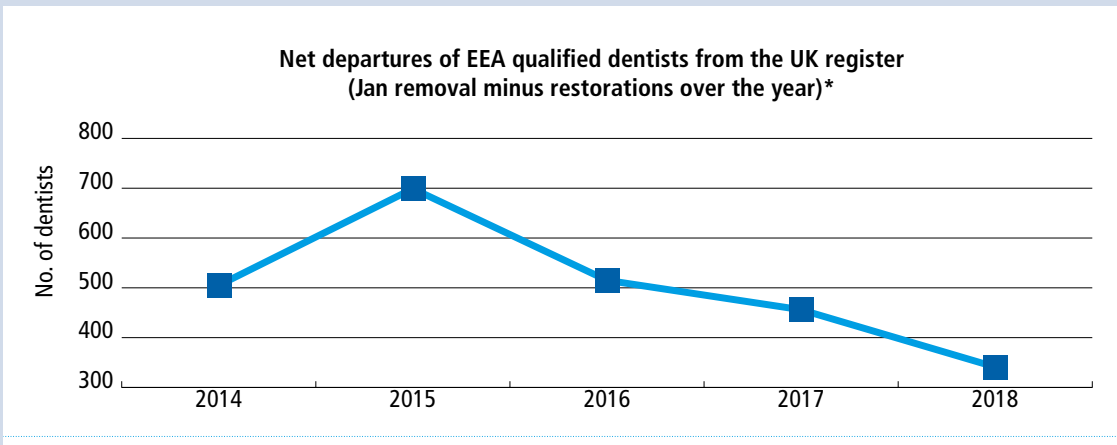

New EEA qualified dentists added to the register each year**

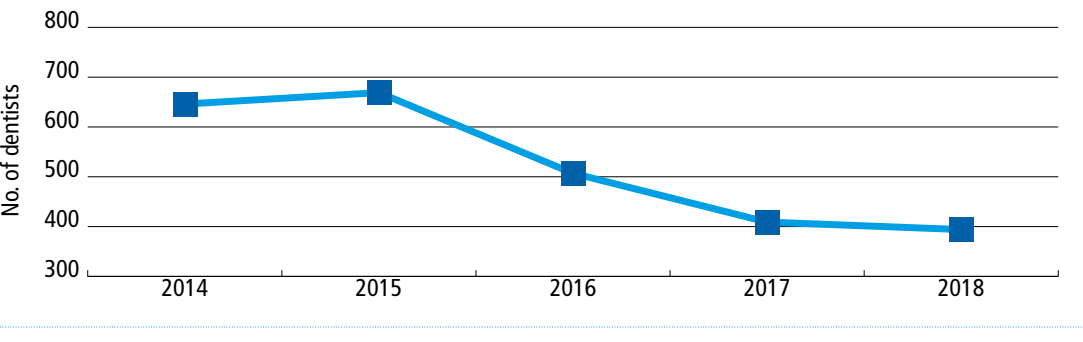

Totals - EEA qualified dentists (as of 31 December each year)

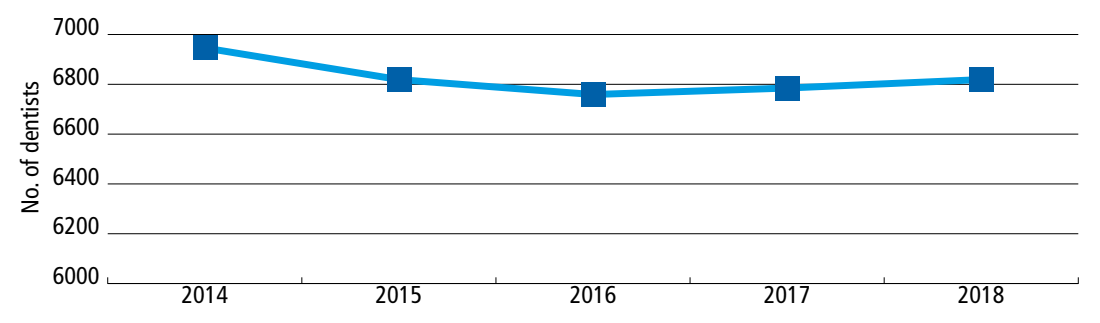

* While dentists do come off the GDC's register throughout the year, and for a host of reasons, January (post ARF) is the largest number

** Dentists who have never been on the UK register before

Source: GDC

Fig. 1 EEA qualified dentists - register figures 


\section{Uncertain future}

As the latest scheduled deadline for the UK to leave the EU approaches on 31 October, the future for dentistry remains uncertain although some people predict the problems in attracting overseas dentists here will be temporary.

Lithuanian-trained associate Rasa

Zamulaityte who qualified in her home country 12 years ago has been based in Bournemouth for around a decade and feels settled despite uncertainties around Brexit.

'Initially I thought I'd just come to the UK for six or nine months for a change, but then I started studying more, decided to stay and got used to being here. Then I fell in love with an English guy and did not want to go back,'she says.

After signing a contract with a dental corporate for a limited time, Rasa decided to extend her time here and after several years working for the NHS, now works three days a week in a private practice and two days in a NHS practice.

She has permanent residency here and says: 'I don't know how dentistry is going to be affected by Brexit. It depends on how the economy will go post-Brexit and how much patients will be able to afford dentistry.

'I don't feel unsettled by Brexit. It just may be harder for corporates to employ dentists from other countries which may create dentist shortages again.

'Having spoken to colleagues and friends from university back in Lithuania, they have said if they wanted to come and work here, they are not going to apply to come here until the Brexit is done.'

Woodrow warns there are other indirect impacts of Brexit to bear in mind, saying: 'We hear that it's not just about the way it makes people feel here, but also the economic impact of it in terms of the value of earnings now in the UK are not what they were.

'That makes it a less attractive place to work for some people from parts of the EU. The pound is considerably weaker than it was three years ago and that also makes materials more expensive.'

Colosseum Dental's Buergin adds: 'Once we have certainty and we know what Brexit implies, the channel will open up again. It is hopefully a temporary problem.'

\section{References}

1. General Dental Council. Survey of European Qualified Dental Professionals Final Report January 2019. Available at: https://www.gdc-uk.org/about/whatwe-do/research (accessed July 2019).

2. Christie \& Co. The Dental Industry 2018: Staffing, Brexit and The Dentist Shortage. October 2018. Available at: https://www.christie.com/christieMediaLibraries/christie/PDFs-Publications/Dental/ CCO-The-Dental-Industry-2018.pdf?ext=.pdf (accessed July 2019).

3. Professional Standards Authority. Annual review of performance 2017/18: General Dental Council. May 2019. Available at: https://www. professionalstandards.org.uk/docs/default-source/ publications/performance-review---gdc-2017-18. pdf?sfvrsn=16db7420_0 (accessed July 2019).

4. LaingBuisson. Dentistry UK Market Report. January 2019. Available at: https://www.laingbuisson.com/ shop/dentistry/ (accessed July 2019).

\section{The bells are ringing out for new content}

The $B D J$ Christmas issue is now a regular feature in the publication calendar, and as in previous years we would like to invite writers to submit content.

Highlights of the 2018 Christmas edition included the research papers Whisky, microwave or hairdryer? Exploring the most efficient way to reduce bacterial colonisation on contaminated toothbrushes and Are dental professionals more likely to consume sweet snacks, over savoury snacks in the workplace?

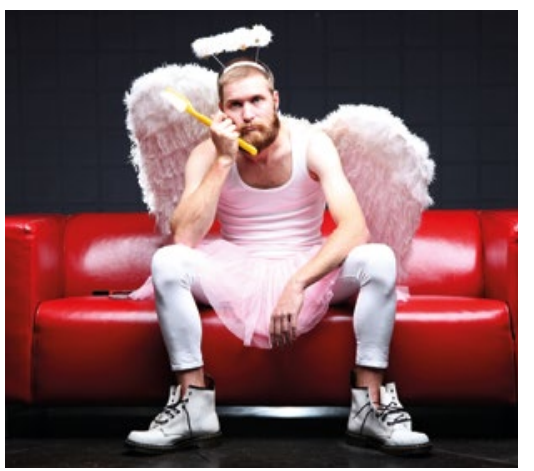

We also published a range of tongue-in-

cheek letters, news and product news stories written by members of the editorial team, all in the spirit and fun of the festive season.

If you have an idea for a funny $B D J$ paper, or a spoof letter or news item, we would like to hear from you. Please email us a description of your proposed topic by 9 September 2019.

We are pleased to consider all kinds of articles, and a Christmas theme is not required.

To submit a proposal, please email News Editor Kate Quinlan on k.quinlan@nature.com. 